\title{
How to Teach Ecology to Students of Environmental Engineering
}

\section{Maria Giulia Cantiani}

Department of Civil, Environmental and Mechanical Engineering, University of Trento, Italy.

\begin{abstract}
The paper illustrates a set of teaching practices applied by the author in the course of Ecology, addressed to third year students of the First Cycle Degree (BSc) in Environmental and Land Engineering, at the University of Trento (Italy). The features of the university context and the main characteristics of these students are described, also referring to changes which have occurred over time. On the basis of a twenty-five-year teaching experience, the author highlights the challenges and opportunities of an approach aimed at involving students in the learning process, raising interest and curiosity towards ecological issues, stimulating students' emotional competencies and their capacity to critically reflect on their own educational experience. In conclusion some comments are made regarding the need for a greater engagement by the academic staff towards non-conventional teaching and learning experiences. In particular, a more integrated method of evaluation of the quality of teaching is sought, effective in taking into account different approaches and techiniques and comparing learning outcomes.
\end{abstract}

Keywords: learning; participative approach; storytelling; fieldtrips; teamwork. 


\section{Introduction}

Being effective, when teaching Ecology in a course of Environmental and Land Engineering, may be a real challenge. I immediately perceived it, when I first started teaching on this course at the University of Trento, coming from a background of Forestry Science studies and research in the early 90s. Since then, many things have changed: first and foremost the higher education system in Italy moved from five-year-degree courses to a three plus two years organization, following the Bologna process and, almost at the same time, each university was given more functional autonomy. Afterwards, various university reforms made by different successive governments generally exerted pressure for budget cuts and affected the university context resulting, among other things, in more compact courses, reduction of the time available for exams and of subjects to be chosen and generally less time available for personal study. Meanwhile, a clear institutional drive towards productivity and competitiveness in research have somehow "distracted" especially the young academic staff from teaching concerns. Following global socio-economic and cultural transformation, the characteristics of students have also radically changed (EU, 2011). Different cultures, languages, family environment and cognitive background shape today very heterogeneous groups of students. All the same, students seem to share a similar attitude in their approach to studying. A picture of Italian university students (Cattani, personal communication) depicts them as generally showing little propensity to delve into an issue and having a poor critical attitude towards problem solving. Despite having access to a multitude of data and information from multimedia sources, rather than being an opportunity, this often turns out to be a limitation. Moreover, the external context is full of stimuli and distractions and school and university are no longer considered the only source of knowledge.

Despite these changes, however, engineering students have over time retained some particular features, mostly linked to the forma mentis itself, which influenced their choice of the study course and, hopefully, of their future profession. They have a general inclination towards logical thinking and, being often gifted in maths, they feel much more comfortable when facing quantitative problems and numerical exercises than when they are requested to deal with qualitative issues and oral presentations. What they expect from their higher education is mainly to gain technical skills. This is also true with regard to environmental engineering students. Depending on the main focus of the study course, ecology is included in the curriculum of the different universities, with differing approaches. In some cases, ecology is mainly treated under a quantitative perspective for modelling purposes or, in other cases, points on chemistry related issues. Environmental engineering students at Trento university are supposed to work, in the future, in direct contact with the territory, in differents domains, from natural hazards management to water management, waste management, landscape conservation, renewable energies, cooperation 
in developing countries and so on. Knowledge of ecological processes is therefore necessary and, for this reason, the teaching approach is basically qualitative, starting with some fundamental biological notions (often lacking in many students) and then deepening the concepts of structure and functions of ecosystems and their natural dynamics. All topics are addressed from the point of view of sustainability, trying to develop in the students a way of thinking that takes sustainability into account. Today, in the light of international scholars' analysis and debate, it is widely recognized that it is necessary to incorporate sustainability-related concepts and content into engineering education and the profession (Leal Filho et al., 2015). Obviously, this is particularly important when dealing with environmental engineering students. However, there is still a lack of knowledge about appropriate methods and tools and a need for information regarding the relationship between career success in engineering profession and wether there have been provisions for sustainability-related capabilities.

\section{Teaching Ecology at the University of Trento}

Ecology is taught as a compulsory subject in the third year of the First Cycle Degree, in the second semester. The course enrols about eighty students, with a slight majority of males (the percentage of males, however, has gone down over time, being around $90 \%$ in the early 90s). Exams are oral and critical analysis skills and capability of synthesis are required.

One of my first concerns is creating the conditions for an interactive, stimulating and, when possible, enjoyable lesson. Students are generally led to play a rather passive, often convenient role during the lessons and it is definitely hard to actively engage them in learning. Most of them have a well grounded theoretical background, but are not familiar with concrete, practical problems. Some of them approach Ecology with a kind of preconceived idea of an easy, "qualitative" subject, not requiring too much effort to prepare and with an exam not too difficult to pass whereas others have many expectations and are happy to be finally confronted with ecological issues, but think they do not have adequate skills to deal with such a study. In general, all of them are quite timid and hesitant when their opinion is requested and some of them do not even dare to ask for an explanation when there is something which is not clear. In such a situation it is dramatically important to stimulate from the beginning curiosity and interest towards the subject, which could hopefully turn into passion and enthusiasm, at least in the most sensitive students. Of primary importance is the need for helping these young people to develop their emotional competencies, according to Goleman's ideas (1995) and, among these, the ability to selfmotivate, empathy, self-awareness, interpersonal effectiveness and communication skills. Building a strong tie with the "real world" outside the classroom and developing the capacity to deal with concrete environmental problems are crucial objectives of the course. 
Acquiring and internalizing the specialist language of the discipline and creating bridges with other disciplinary contexts are other equally important aims. Finally, a meaningful learning in ecology involves overcoming the primacy of the Cartesian approach, typical of other subjects and implies a break with the traditional approaches, also in order to instill in students more responsibility for their own learning (Iori, 2010, Rogers \& Freiberg, 1969).

For these aims, different activities are carried out throughout the semester, starting with an "ice breaking” workshop in the very first lesson. There are structured activities, such as practical exercises in workgroups or fieldtrips, which are carried out each year in particular parts of the course. There are then other practices I resort to when there is an opportunity and I think they may be helpful in keeping alive the students' motivation during the course. But it is also necessary to hold students' attention during the entire lesson (even a threehour lesson!). With regard to this, many microactivities may, when necessary, help. Among these a simple change of setting inside the classroom or a short walk outside to do botany for real (a "hop" outside the classroom) may be effective. In the following subsections some of the main practices experimented during my work as a teacher are presented. Of course, depending on the case, each of them can help to achieve one or more of the abovementioned goals.

\subsection{The "ice breaking" workshop}

A question is written on the blackboard "What is the importance of being green in colour?" and students are invited to organize themselves in small groups. Each group is given a black marker and some cards of a certain shape and color. Specific indications and explanations are given only if expressly requested and students are left free to exchange ideas on the topic, discuss and finally summarise in a short sentence, on each card, each idea formulated by the group. Examples of possible ideas are: “Green coloured living things are important because they photosynthesise and therefore purify the air", "Plants are important sources of raw material” or "Green areas are relaxing and help mental health". At the end of this first step, a spokesman from each group is asked to attach the cards onto a specific section of the blackboard or the wall. Then, with a general discussion and the help of the spokesmen, the cards relating to the same or a similar theme are brought together (figure 1) and a logical title for these new sections is proposed (for example "Productive function of ecosystems" or "Recreation" and so on). This exercise, lasting a couple of hours, is useful both for students and for the teacher. For students it is a clear sign that their active participation in the lessons is welcome and it is a good aid to overcome shyness and get involved in dialogue with classmates. For the teacher the results are a thermometer of how the relative importance of the different goods and services furnished by the ecosystems has changed over time in the perception of young people. For example, a clear shift has been noticed from when students attributed the main importance to the protective and productive functions of forest ecosystems, as happened in the early 90s, to the present, 
when they value much more the role of urban green for human well-being or they place emphasis on ethical issues. Moreover, the results give the teacher an idea of students' previous biological knowledge.

\subsection{Practical exercises in the classroom}

During the semester, practical exercises in the classroom are scheduled on different topics. Students are invited to work in small groups on the identification of the main local tree species, or for the realization of climatic diagrams. The botanical exercises are particularly loved by students, due to the fact that they are put in direct contact with the objects of their study. Even students who do not regularly attend classes do not want to miss this opportunity. In particular, the first botanical exercise, when students are faced with twigs without leaves, in winter habitus, is considered very satisfying, because it is experienced as a real challenge.

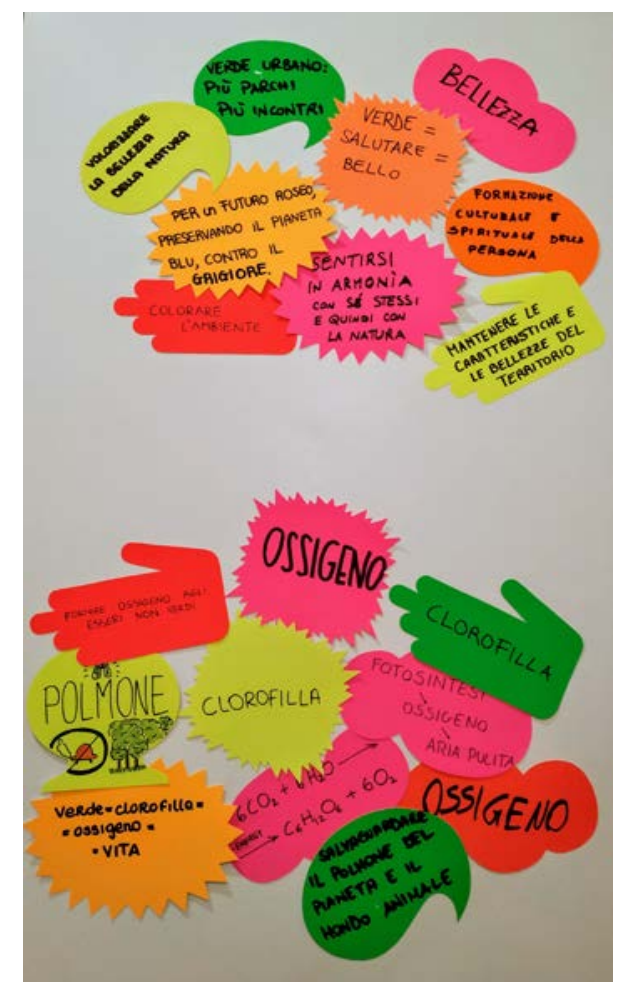

Figure 1. Students' ideas from the "ice breaking” workshop 


\subsection{Fieldtrips}

The fieldtrips have always been considered the particularity of the course of Ecology at the University of Trento, and students ask right at the beginning of the course, if they will go on them and where. Half a day or the entire day is spent outdoors in different mountain areas of the province of Trento, often meeting technicians working in the territory, in order to discuss different topics: the management of natural resources, landscape conservation and soil protection. These activities produce many different positive outcomes: they put students in direct contact with concrete issues, thus opening new perspectives, they allow students to address different technicians operating in the field and to talk about environmental problems with them as peers, they facilitate the development of technical language and last, but not least, they foster the creation of a familiar, informal atmosphere, where any person feels free to express his or her personal opinion and to ask questions. Even if the fieldtrips take place mainly towards the end of the course, when the temptation to stay home to study for the exams is strong, the students generally participate in large numbers.

\subsection{Inversion of roles}

Students are asked, as a voluntary task, to prepare in teams a lesson on a specific theme, on the basis of material provided by the teacher and with the teacher's help if requested. They are free to organize the presentation in the way they deem the most convenient and, after that, time for a general discussion is allowed. Despite the fact that not all students are willing to launch into such a task, this exercise is however very helpful. In fact students find it much easier to discuss a topic with their peers and finally they have proof that, if their classmates can do it, then they can too and they may feel encouraged to try themselves next time.

\subsection{Meetings with previous students}

When it is possible, I organize meetings with previous students currently working in different fields and making use of ecological concepts and knowledge somehow. There may be people working for public bodies or freelance practitioners or researchers. They describe their activity in a few words and then answer students' questions, which are generally very numerous. In other cases students who are carrying out their master thesis on issues close to those of ecology come to talk about their work. Their presentation may constitute the development of a topic dealt with during a class.

\subsection{Creating scenarios}

This is an interesting task that all students have to fulfill at a specific point of the course, just before that part of the course which deals with the natural ecosystem dynamics. The idea is that, once provided with all the basic notions of ecology, students should be able to 
resort to all their knowledge in order to hypothesize the possible natural ecosystem trends, starting from different initial situations, as suggested by the teacher. This work, generally considered quite difficult by students, requires a good effort in synthesising and, being carried out in small groups, stimulates the capacity for reflection and argumentation.

\subsection{Storytelling}

Since the beginning of my teaching experience, I have realized that a narrative style may be very helpful. Of course not all topics may be addressed with such an approach, but in many cases, transforming an explanation into a story may really make a difference. For example, the development of life on the planet may be a boring sequence of events or become the fascinating story of Life. In the same way, the structures and functions of trees may be just described by means of words and images or, putting students in the "shoes" of a tree, may be understood and appreciated as a revolutionary and smart way to be live beings. To appeal to people's emotions is not simply a means to stimulate curiosity and interest. Indeed, feelings and emotions are critical in the process of construction of knowledge and generation of individual authonomous thinking (Bruner, 1996; Dallari, 2012). Narrative thinking, though being creative, transversal and discontinuous, is at the basis of logical thinking, nevertheless (Smorti, 1994).

\section{Conclusions}

I am not a specialist in education and I do not carry out specific research regarding this. My experimentation in this field is mainly based on my previous personal experience as a forestry student (expecially with regard to practical exercises and fieldtrips) or is inspired by my research work on participative planning of natural resourses management. Finally, I have always had a personal aptitude towards the narrative style. For this reason I never thought of designing an experimental method in order to measure somehow the outcomes of my approach. Only recently I felt the need for starting to conceptualise it, deeming extremely important reflection on the effectiveness of teaching, especially in the scientific and technical domain. I have always looked for feedback, of course, but this was mainly based on students' direct appreciation, on their results at the exams, on the number of theses in ecology I was asked to be tutor for and finally on the requests of information and advice on the part of previous students. Unfortunately, until today, the need for an evaluation of didactic activities has been disregarded, especially at national level. This is also due to the fact that a succesful teaching activity is generally not taken into consideration in the process of evaluation of the members of academy, either at national or local level. But things are finally starting to change and a major awareness of the necessity of caring about didactic skills is now advancing, even at ministerial level. Actually, the University of Trento, since 1995, has been giving the students questionnaires, in order to evaluate the quality of the 
different courses offered in some faculties. Today, such questionnaires have been standardized following the instructions of the Ministry of Education and are compulsory for all students. The problem is that such questionnaires have been designed with only the conventional approach in mind and the results are not particularly meaningful. However, things seem destined to change, starting from the local level. The University of Trento has made a Strategic Plan, aiming at more effective teaching (University of Trento 2018). Action 3 of such a plan fosters the experimentation of innovative teaching approaches. In this academic year (2018-2019), for the first time, a cycle of seminars on didactic skills, has been expressely created for young teachers, but it has also been attended by many older teachers. It has been a great success and people have largely taken the chance to finally meet, to compare ideas and discuss the topic. Eventually, such reflections seem to be starting to make inroads at national level too.

\section{References}

Bruner, J. (1996). The Culture of Education. Harvard University Press Cambridge.

Dallari, M. (2012). Testi in testa. Parole e immagini per educare conoscenze e competenze narrative. Centro Studi Erickson Trento.

European Union (2011). The Future of Learning: Preparing for Change. http://ipts.jrc.ec.europa.eu/publications/pub.

Goleman, D. (1995). Emotional Intelligence. New York: Bantam Books.

Iori, V. (2010). Vita emotiva e formazione. Education Sciences \& Society, 1(2), 37-49

Leal Filho, W., Azeiteiro, U.M., Caeiro, S., \& Alves, F. Eds. (2015). Integrating Sustainability Thinking in Science and Ingeneering Curricula: Innovative Approaches, Methods and Tools. Springer XII. http://www.springer.com/gp/book/9783319094731

Rogers, C., \& Freiberg, H.J. (1969). Freedom to learn. $3^{\text {rd }}$ ed. New York: Macmillan Publishing

Smorti, A. (1994). Il pensiero narrativo. Giunti Firenze.

University of Trento (2018). FormId: Centro di competenza per la formazione dei docenti e l'innovazione didattica. https://www.unitn.it/ 